\title{
Response to Anthracnose and Germination Rate of Colletotrichum Sublineola Acervuli of Greenhouse-Grown Sorghum
}

\author{
Louis K. Prom* \\ USDA-ARS, Plains Area, College Station, Texas 77845, United States \\ Thomas Isakeit \\ Department of Plant Pathology and Microbiology, Texas A\&M University, College Station, TX 77843, United States \\ Ghada Radwan \\ Faculty of Science, Port Said University, Port Said 42521, Egypt
}

\begin{abstract}
Colletotrichum sublineola, the causal agent of sorghum anthracnose, infects all above ground parts of the crop. The most pronounced phase of the disease is its foliar phase. In this study, 10 sorghum lines with checks were evaluated in the greenhouse for resistance against C. sublineola. Acervuli germination rate within infected leaves was also recorded. All the 10 sorghum lines along with checks BTX623, TAM428, and PI609251 were susceptible and as expected, SC748 was resistant. Variation among the lines for acervuli germination rate was observed; TAM428 and 1110248 recorded the highest percentage (98.3\%) while PI609251 exhibited the lowest rate of acervuli germination (33.3\%). Conidia produced from germinating acervuli are critical to the distribution and spread of the disease. However, conidia produced within the acervuli do not usually germinate due to the presence of self-inhibitor compounds. Thus, these self-inhibitors that may occur in the acervuli could explain the difference in levels of susceptibility among sorghum germplasm.
\end{abstract}

Keywords: Sorghum bicolor; Anthracnose; Acervuli; Germination rate; Colletotrichum spp.

(9) (9) CC BY: Creative Commons Attribution License 4.0

\section{Introduction}

Sorghum anthracnose is the most destructive disease worldwide. The pathogen, Colletotrichum sublineola infects the stalk, foliage, panicle, and grain, thereby degrading the quantity and quality of both grain and stover [1, 2]. The foliar phase of the disease is the most devastating, resulting in yield losses as high as $50 \%$ in susceptible lines, especially when infection is followed by wet and dry cycles during periods of high temperatures [3-7]. Although management strategies such as crop rotation and use of fungicides may reduce the impact of the disease, the utilization of resistant lines is the most effective means for control. However, the occurrence of different pathotypes within the pathogen population of $C$. sublineola offers challenges in breeding for durable resistance [813].

In this short communication, we report reaction to anthracnose and the germination rate of Colletotrichum sublineola acervuli in greenhouse-grown sorghum.

\section{Materials and Methods}

Ten sorghum lines, including three susceptible checks BTx623, TAM428, and PI609251, and the resistant check SC748 were planted in the greenhouse. Seeds were planted in pots containing Metro-Mix 200 potting medium, and placed in the greenhouse at $25^{\circ} \mathrm{C}$. Each line was replicated three times in a randomized complete block design.

Inoculation and disease assessment were conducted using the methods described by Prom, et al. [14]. Briefly, at $30 \mathrm{~d}$ after planting, plants were inoculated by placing $10 \mathrm{C}$. sublineola-colonized grains into plant whorls. Additionally, for the spray inoculation, approx. $5 \mathrm{ml}$ of conidial suspension $\left(10^{6}\right.$ conidia. $\left.\mathrm{mL}^{-1}\right)$, with Tween 20 $(0.5 \mathrm{ml} / \mathrm{L})$ added to the inoculum, was deposited on the leaves of each plant. Shortly after spraying the inoculum, plants were misted for $30 \mathrm{sec}$ at $45 \mathrm{~min}$ intervals, $10 \mathrm{hr} / \mathrm{d}$ for one month. Misting regime provides favorable environment for infection and disease development. Disease assessments were conducted $30 \mathrm{~d}$ post-inoculation and for two more weeks at 7-d intervals using a scale of 1 to $5[14,15]$, where $1=$ no symptoms or chlorotic flecks; $2=$ hypersensitive reaction (reddening or red spots) on inoculated leaves but no acervuli formation; $3=$ lesions on inoculated leaves with acervuli in the center; $4=$ necrotic lesions with acervuli bottom and middle leaves; and $5=$ most leaves, including the flag leaf containing abundant acervuli. Each pot was assigned a single score value based on the reaction of the plants. The symptom types were then categorized into two reaction types, resistant $=$ rated as 1 or 2 ; and susceptible $=$ rated as 3,4 , or 5 .

\subsection{Percent $C$. Sublineola Erumpent Acervuli}

Infected leaves from each line were cut and placed in labeled paper bags and transported to the laboratory for processing. Leaves from each line were cut into pieces and surface disinfested separately by placing them in $10 \%$ 
NAOCl for 30 sec., rinsed three times in sterile distilled water, and dried under a laminar flow hood. Three leaf pieces from each line were placed on Petri dishes containing half-strength potato dextrose agar and incubated at $28^{\circ} \mathrm{C}$. The plated leaf pieces were examined microscopically at $48 \mathrm{~h}$ and $72 \mathrm{~h}$, respectively. Percent germination rate was based on the number of erumpent acervuli that showed the oozing of conidia in a mucoid or gelatinous mass (Fig. 1) over the total number of non-erumpent acervuli present within the view area under the microscope at magnification $\mathrm{x} 40$.

\subsection{Statistical Analysis}

Data for the $48 \mathrm{~h}$ and $72 \mathrm{~h}$ were combined before the analysis. PROC ANOVA (SAS version 9.4, SAS Institute, Cary, NC) was used to analyze the germination rate of the acervuli on the infected sorghum lines. The germination rate means among the lines were compared using the Tukey-Kramer for multiple comparisons at the 5\% probability.

Table-1. Disease response and percent germination rate of Colletotrichum sublineola acervuli of different sorghum lines
\begin{tabular}{l|l|l}
\hline Line & Reaction type & \% Germintaion rate \\
\hline TAM428 & S & $98.3 \mathrm{a}^{3}$ \\
\hline $11-10248$ & S & $98.3 \mathrm{a}$ \\
\hline BTx623 & S & $96.3 \mathrm{a}$ \\
\hline RTx430 & S & $93.3 \mathrm{a}$ \\
\hline $11-6143$ & S & $96.3 \mathrm{a}$ \\
\hline $11-10212$ & $\mathrm{~S}$ & $92.0 \mathrm{a}$ \\
\hline $11-6078$ & $\mathrm{~S}$ & $79.7 \mathrm{a}$ \\
\hline $11-6138$ & $\mathrm{~S}$ & $92.0 \mathrm{a}$ \\
\hline $11-10239$ & $\mathrm{~S}$ & $89.3 \mathrm{a}$ \\
\hline $11-6266$ & $\mathrm{~S}$ & $73.0 \mathrm{ab}$ \\
\hline $11-10213$ & $\mathrm{~S}$ & $76.7 \mathrm{a}$ \\
\hline $13-5654-2$ & $\mathrm{~S}$ & $61.7 \mathrm{ab}$ \\
\hline PI609251 & $\mathrm{S}$ & $33.3 \mathrm{bc}$ \\
\hline SC748-5 & $\mathrm{R}$ & $0.0 \mathrm{c}$ \\
\hline
\end{tabular}

${ }^{1}$ Plants were evaluated for resistance to anthracnose in the greenhouse.

${ }^{2}$ Disease assessment was based on a scale of 1 to $5[14,15]$, where 1 = no symptoms or chlorotic flecks; $2=$ hypersensitive reaction (reddening or red spots) on inoculated leaves but no acervuli formation; $3=$ lesions on inoculated leaves with acervuli in the center; $4=$ necrotic lesions with acervuli bottom and middle leaves; and $5=$ most leaves, including the flag leaf containing abundant acervuli. Each pot was assigned a single score value based on the reaction of the plants. The symptom types were then categorized into two reaction classes, resistant $=$ rated as 1 or 2 (Fig. 1); and susceptible $=$ rated as 3, 4, or 5 (Fig. 2).

${ }^{3}$ Means within a column followed by the same letter(s) are not significant $(P=0.05)$ based on the TukeyKramer adjustment for multiple comparisons.

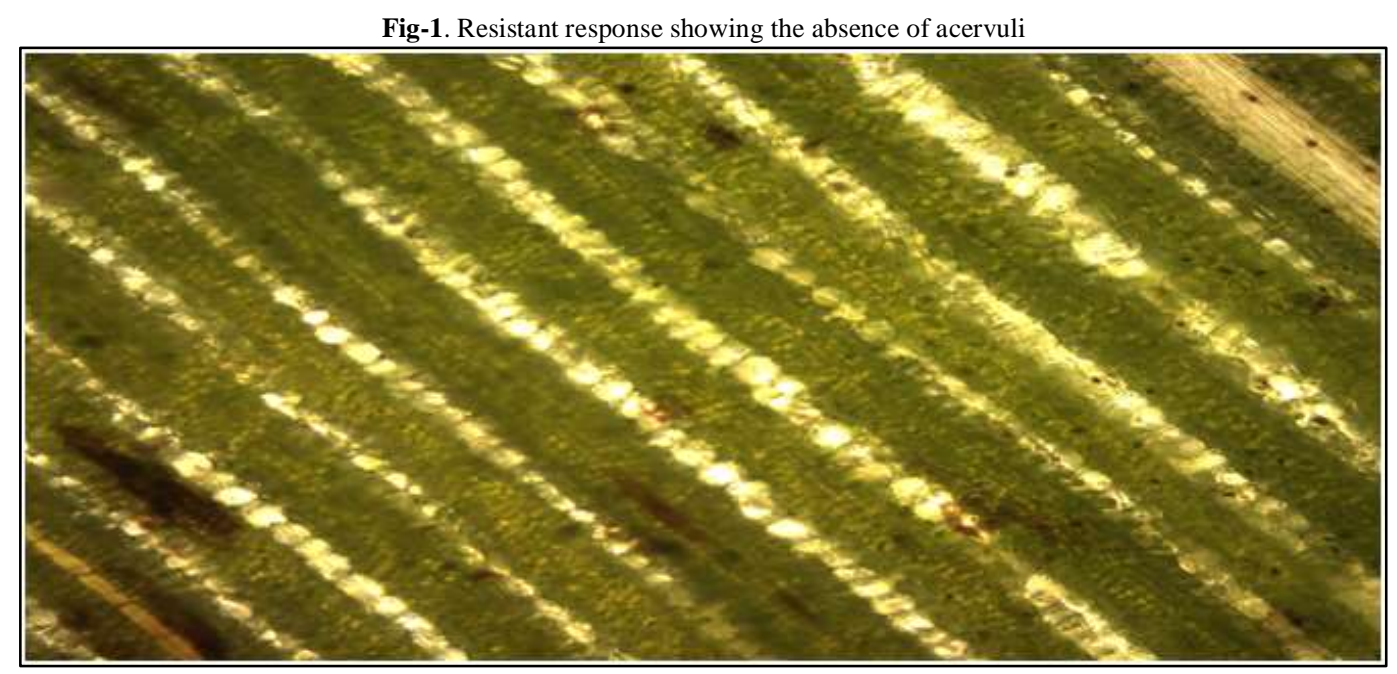


Fig-2. Susceptible response showing erumpent acervuli with setae and the oozing of conidia in a mucoid or gelatinous mass

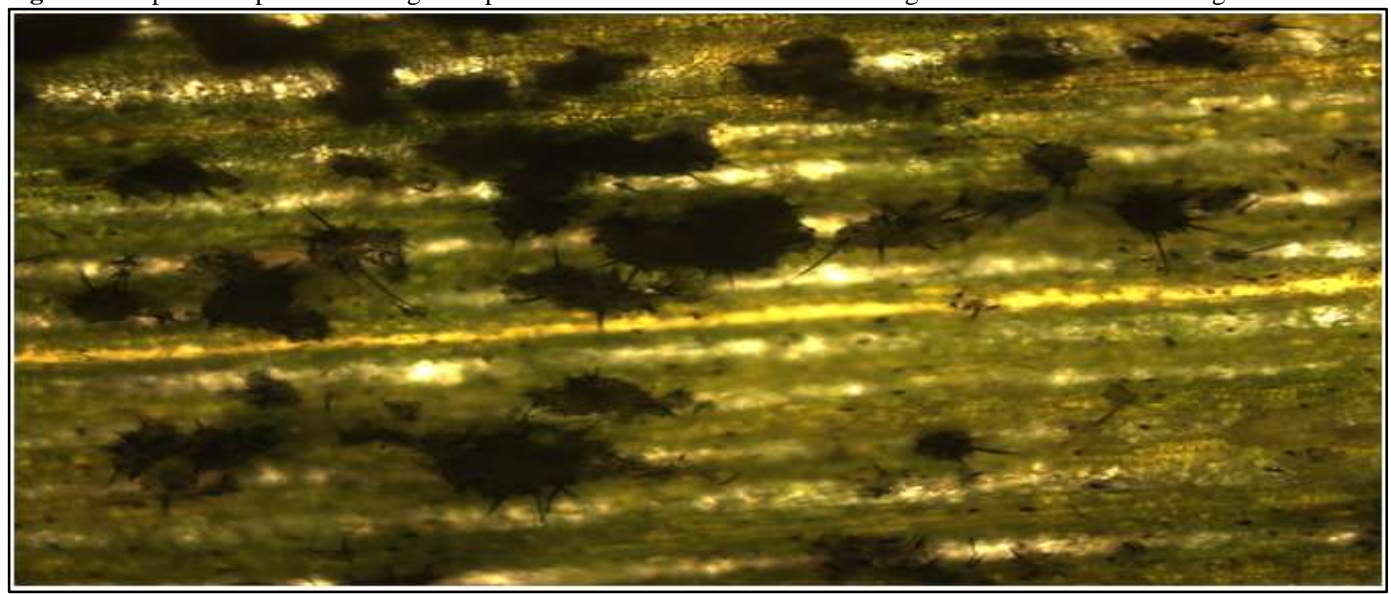

\section{Results and Discussion}

This study was conducted in the greenhouse to identify resistant sources among 10 sorghum lines. The 10 sorghum lines evaluated in this study, including checks BTx623, TAM428, and PI609251 were all susceptible when challenged with $C$. sublineola in the greenhouse and as expected SC748 was resistant to the disease (Table 1).

Nevertheless, a large number of sorghum lines with anthracnose resistance have been identified previously in both field and greenhouse evaluations [1, 2, 15-18]. However, the hyper-variability of $C$. sublineola requires continual screening to identify resistant sources, especially sorghum lines with different resistance genes.

In addition, to the disease reaction, variation in acervuli germination rate among the sorghum lines was also observed. TAM428 and sorghum line 1110248 exhibited the highest acervuli germination rate $98.3 \%$ and this level was significantly higher than the rate recorded for one of the susceptible checks PI609251 (33.3\%). Conidia produced from germinating acervuli are critical in the distribution and spread of the disease within the field and other areas. Studies have shown that Colletotrichum spp.' conidia in mucoid or gelatinous mass within the acervuli do not germinate due to the presence of mycosporine-alanine, a self-inhibitor of germination in the mucilage [19, 20]. This self-inhibition of the conidia within the mucilage of the acervuli prevents premature germination and allows for dispersal and subsequent germination in a favorable environment such as, landing on a suitable host plant [19, 20]. The self-inhibitor compounds can be found in different areas such as outside of the conidia cells, inside the mucilage of acervuli, or associated with the spore cell walls [19]. This mechanism of self-inhibition may have played a role in the rate of acervuli germination, resulting in the difference among the sorghum lines evaluated in this study. Further research is needed to determine whether the levels of endogenous inhibitors in mucilage of germinating acervuli, or in non-erumpent acervuli, of susceptible sorghum lines could explain differences in the levels of anthracnose response.

\section{Reference}

[1] Sharma, R., Upadhyaya, H. D., Manjunatha, S. V., Rao, V. P., and Thakur, R. P., 2012. "Resistance to foliar diseases in a mini-core collection of sorghum germplasm." Plant Dis., vol. 96, pp. 1629-1633.

[2] Thakur, R. P. and Mathur, K., 2000. Anthracnose.” pages 10-12 in: Compendium of sorghum diseases. R. A. Frederiksen and g. N. Odvody, eds. USA: The American Phytopathological Society. St. Paul, MN.

[3] Harris, H. B., Johnson, B. J., Dobson Jr., J. W., and Luttrell, E. S., 1964. "Evaluation of anthracnose on grain sorghum." Crop Sci, vol. 4, pp. 460-462.

[4] Hulluka, M. and Esele, P., 1992. Sorghum diseases in eastern africa. Sorghum and millets diseases: A second world review. W. De milliano, r. Frederiksen, and g. Bengston (eds.), . Patancheru, India: ICRISAT, pp. 21-24.

[5] Thomas, M. D., Sissoko, I., and Sacco, M., 1995. "Development of leaf anthracnose and its effect on yield and grain weight of sorghum in west Africa." Plant Dis., vol. 80, pp. 151-153.

[6] Waniska, R. D., Venkatesha, R. T., Chandrashekar, A., Krishnaveni, S., Bejosano, F. P., Jeoung, J., Jayaraj, J., Muthukrishnan, S., and Liang, G. H., 2001. "Antifungal proteins and other mechanisms in the control of sorghum stalk rot and grain mold." J. Agri. Food Chem., vol. 49, pp. 4732-4742.

[7] Warren, H. L., 1986. Leaf anthracnose. Compendium of Sorghum diseases. R. A. Frederiksen, ed. The American Phytopathological Society, St. Paul, MN., pp. 10-11.

[8] Cardwell, K. F., Hepperly, P. R., and Frederiksen, R. A., 1989. "Pathotypes of Colletotrichum graminicola and seed transmission of sorghum anthracnose." Plant Dis., vol. 73, pp. 255-257.

[9] Casela, C. R., Ferreira, A. S., and Schaffert, R. E., 1992. "Physiological races of Colletotrichum graminicola in Brazil." In Sorghum and Millets Diseases: A Second World Review. W. de Milliano, R. Frederiksen, and G. Bengston (Eds.), Patancheru, India. ICRISAT. pp. 209-212.

[10] Moore, J. W., Ditmore, M., and TeBeest, D. O., 2008. "Pathotypes of Colletotrichum sublineolum in Arkansas." Plant Dis., vol. 92, pp. 1415-1420. 
[11] Pande, S., Mughogho, L. K., Bandyopadhyay, R., and Karunakar, R. I., 1991. "Variation in pathogenicity and cultural characteristics of sorghum isolates of Colletotrichum graminicola in India." Plant Dis., vol. 75, pp. 778-783.

[12] Prom, L. K., Perumal, R., Erattaimuthu, S. R., Little, C., No, E. G., Erpelding, J. E., Rooney, W. L., Odvody, G. N., and Magill, C. W., 2012. "Genetic diversity and pathotype determination of Colletotrichum sublineolum isolates causing anthracnose in Sorghum." Eur. J. Plant Patho., vol. 133, pp. 671-685.

[13] Valèrio, H., Rèsende, M., Weikert-Oliveira, R., and Casela, C., 2005. "Virulence and molecular diversity in colletotrichum graminicola from Brazil." Mycopathologia, vol. 159, pp. 449-459.

[14] Prom, L. K., Perumal, R., Erpelding, J. E., Isakeit, T., Montes-Garcia, N., and Magill, C., 2009. "A pictorial technique for mass screening of sorghum germplasm for anthracnose (Colletotrichum sublineolum) resistance." The Open Agric. J., vol. 3, pp. 20-25.

[15] Erpelding, J. E. and Prom, L. K., 2004. "Evaluation of Malian sorghum germplasm for resistance against anthracnose." Plant Pathol. J., vol. 3, pp. 65-71.

[16] Cuevas, H. E., Prom, L. K., Isakeit, T., and Radwan, G., 2016. "Assessment of sorghum germplasm from Burkina Faso and South Africa to identify new sources of resistance to grain mold and anthracnose." Crop Prot., vol. 79, pp. 43-50.

[17] Erpelding, J. E., 2010. Anthracnose resistance in sorghum breeding lines developed from Ethiopian germplasm. Plant Health Progress.

[18] Prom, L. K., Erpelding, J., Perumal, R., Isakeit, T., and Cuevas, H., 2012. "Response of sorghum accessions from four African countries against Colletotrichum sublineolum, causal agent of sorghum anthracnose." American J. Plant Sci., vol. 3, pp. 125-129.

[19] Chitarra, G. S., Abee, T., Rombouts, F. M., Posthumus, M. A., and Dijksterhuis, J., 2004. "Germination of Penicillium paneum conidia is regulated by 1-Octen-3-ol, a volatile self-inhibitor." Appl. Environ. Microbiol., vol. 70, pp. 2823-2829.

[20] Leite, B. and Nicholson, R. L., 1992. "Mycosporine-alanine: A self-inhibitor of germination from the conidia mucilage of colletotrichum graminicola." Exp. Mycol., vol. 16, pp. 76-86. 